\title{
From the Editor-in-Chief's Desk
}

\author{
Mark S. George, MD [Editor-in-Chief] \\ Brain Stimulation, Distinguished Professor of Psychiatry, Radiology and Neurology, Medical \\ University of South Carolina, Charleston, SC USA
}

\begin{abstract}
Welcome to the first issue of Brain Stimulation: Basic, Translational, and Clinical Research in Neuromodulation. As you read through this inaugural issue, I hope that you are pleased with the contents. I am.
\end{abstract}

The journal will likely change and shift its focus slightly over time, and not every single issue will reflect every aspect of the journal. Nevertheless, we have worked hard to make the first issue reflect several important principles that are at the heart of Brain Stimulation.

First and foremost, we are agnostic with respect to the current brain stimulation techniques, and appropriately we have articles on TMS, VNS, DBS, ECT, and tDCS all within this first issue. We are not now, and will not be, as long as I am Editor-in-Chief, a journal devoted to any one technique, or one disease or specialty. This open-minded but critical, non-pigeonholed approach is key to the success of the journal (see figure 1). We hope with each issue to reinforce the notion that there is an overlapping emerging science within the larger field of brain stimulation, with commonalities across the different techniques, approaches, and uses.

Second, we also have a range of the type and topics of articles from letters to clinical trials, to cognitive neuroscience, to more theoretical neuroscience and bioengineering reviews. This range of techniques and focus is important for the journal to succeed in its mission of helping to launch a new synthetic approach to brain stimulation.

Dr. Harold Sackeim's founding editorial in this issue captures some of these ideas. In short, the field of brain stimulation, which is emerging at the moment from many disparate areas, needs to begin thinking about underlying unifying themes and principles that transcend the many distinct aspects of the current landscape (see figure 2).

Perhaps not accidentally, I am reading an interesting book at the moment, Consilience, by the Harvard entomologist E.O. Wilson.(1) Wilson credits the philosopher William Whewell with coining the term 'consilience' in his 1840 book, The Philosophy of the Inductive Sciences. (2) Consilience occurs when there is a 'jumping together' of knowledge by the linking of facts and fact-based theory across disciplines to create a common groundwork of explanation. Whewell wrote, "The consilience of inductions takes place where an induction, obtained from one class of facts, coincides with an induction obtained from another different class. This Consilience is a test of the truth of the Theory in which it occurs.'

I profoundly hope that this journal can promote consilience in our exciting new field. I want facts to 'jump together' across classes. The first possibilities are right in front of us as lowhanging fruit. For example, within this issue, do the theories of gating and metastatic

Publisher's Disclaimer: This is a PDF file of an unedited manuscript that has been accepted for publication. As a service to our customers we are providing this early version of the manuscript. The manuscript will undergo copyediting, typesetting, and review of the resulting proof before it is published in its final citable form. Please note that during the production process errors may be discovered which could affect the content, and all legal disclaimers that apply to the journal pertain. 
homeoplasticity, which are so frequency dependent, apply equally to other forms of stimulation and not just TMS? Do they mesh completely with stimulation facts emerging from LTD and LTP? What is the implication for the behaviors we have subjects doing while they receive clinical brain stimulation techniques? In other articles, can the steering of DBS currents and fields, so elegantly described by McIntryre in this issue, also apply to tDCS and even TMS? Do the Sackeim and colleagues rules about how best to assess cognitive deficits apply to other forms of brain stimulation and not just ECT?

The journal Brain Stimulation is thus all about consilience and cross-fertilization. We are experimenting with multiple different ways of accomplishing this cross-talk mission. For those of you who may have reviewed some of the articles in this issue, you may have been asked to 'stretch'. At the level of initial peer review we are purposefully soliciting reviews from outside of the classic pigeonholes - e.g. bioengineers and neuroscientists are reviewing on clinical papers. I am encouraging, but not yet demanding, that authors include a section in the discussion describing how their specific findings might apply to other forms of brain stimulation. We will encourage letters as well, and will likely ask experts in other disciplines to formally comment on manuscripts... all attempting to create consilience and new ways of approaching the field.

Speaking of reviewers and editors, I wish to thank the members of our expert editorial group. Examining the list on page XX you will see that we have labored to get a truly international, multidisciplinary group. We have over 13 countries represented, with experts in most of the current brain stimulation techniques. We are still searching for a good deputy editor for basic neuroscience. This is a key position for the right person to help with our consilience quest. The Editorial Board Membership is by no means exhaustive or complete, meaning that we could not include everyone and there are many, many experts who are not yet involved with the journal. We mean no offense with the initial rollout, and we will be rotating membership and constantly bringing in new experts. I have been amazed at the nearly universal enthusiastic responses to our mention of the journal, and what we hope to create. We have only had 2 declines for membership, which is exceptional for overworked world-class academics. The Editorial Board members realize that we are at the beginning of a new science that melds elements of electronics and biophysics, electrophysiology, imaging, neurophysiology, cellular biology, neuropharmacology, systems level neuroscience, neurology and psychiatry. We are launching this journal to promote, reflect and shape the vitality of this field. We will consider papers as long as some form of focal stimulation is used -electrical, magnetic, ultrasound, pharmacological, etc. Brain Stimulation aims to address the practical as well as the theoretic, striving to capture the best of both worlds. Our goal is to provide a single source for the most important studies in all areas related to neuromodulation, spanning scientific disciplines and medical and surgical specialties.

Each quarterly issue of Brain Stimulation will present original scientific, translational, and clinical research in the field. Basic science topics will include the effects of stimulation on brain processes, the biophysics and biopsychophysics of stimulation approaches, and the use of these techniques to study patterns of neural connectivity. An equal emphasis will be placed on the therapeutic applications and adverse effects of stimulation techniques-not just clinical trials, but also conceptual pieces, consideration of ethical issues, and other issues related to the use of these new technologies to treat human diseases.

Be aware that the journal also has a website, http://brainstimjrnl.com, where subscribers can access the full content, as well as additional content such as videos of brain stimulation procedures and techniques, early-release papers, and clinical trial listings. The journal is immediately available through Science Direct, with Medline listing likely coming after launch. 
So, enjoy the first issue. Please send me informal comments directly, or formal letters we can publish, about the journal. I welcome new ideas about topics (content) and process. Should we have formal debates on controversial ideas, or forced commentary from outside of disciplines on each paper? Should we print publishing standards for the field? That is, exactly what needs to be reported in every TMS article concerning the coil, and pulse and delivery setup? Let me know your thoughts.

I consider my job as editor-in-chief a service position to you, the readers of the journal and the members of this exciting new discipline of brain stimulation. Thanks for the opportunity, and stay tuned for future editions.

\section{References}

1. Wilson, EO. Consilience. New York: Random House; 1998.

2. Whewell, W. The Philosophy of the Inductive Sciences: Founded Upon Their History. London: J.W. Parker; 1847. 


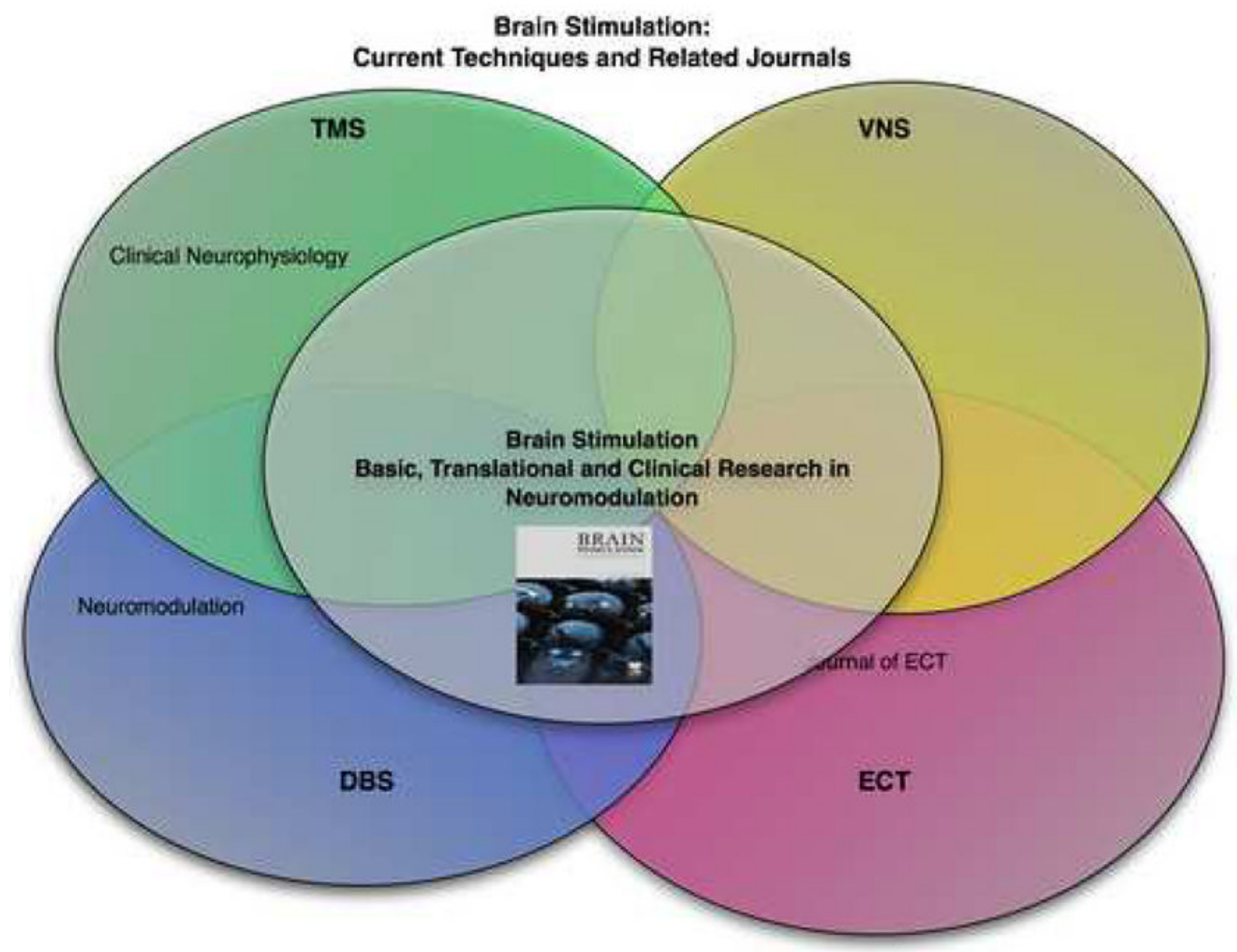

Figure 1.

Current Brain stimulation techniques, and the intended location of this journal. 


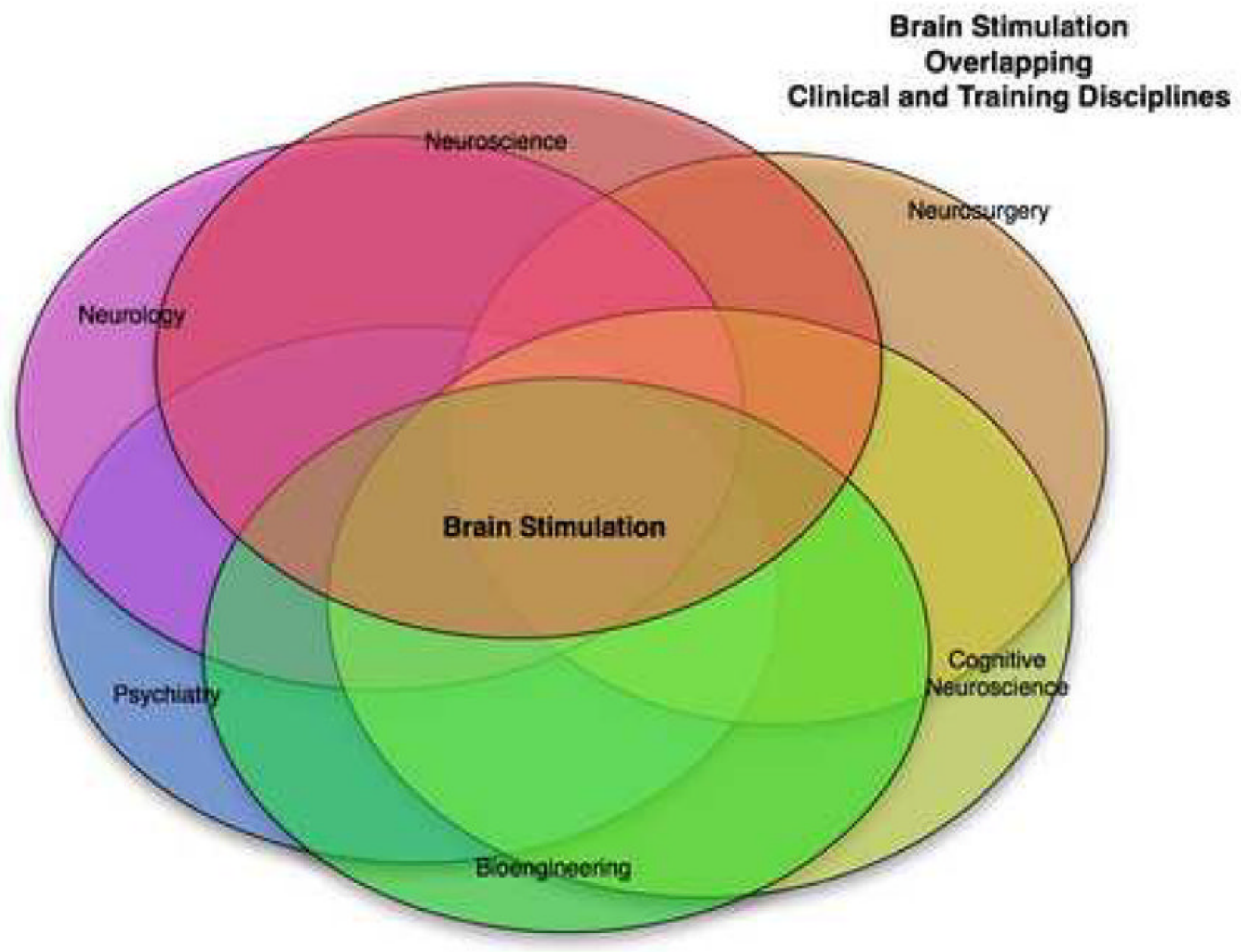

Figure 2.

The current brain stimulation disciplines. 


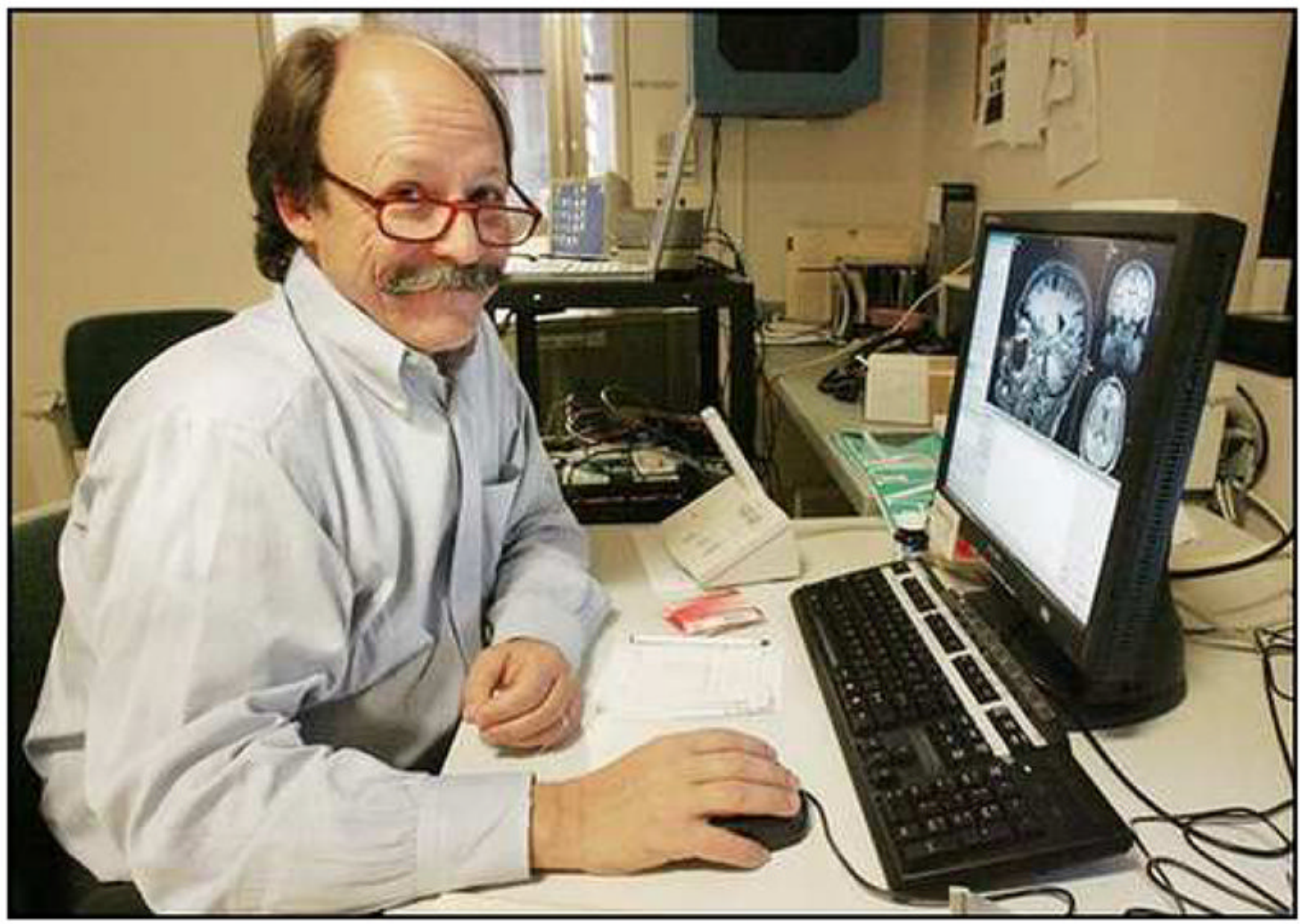

Figure 3.

Mark S. George, MD

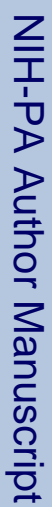

